\title{
ASSESMENT OF CARDIOVASCULAR BEHAVIOURAL RISK FACTORS IN MEDICAL STUDENT
}

\author{
MANOJ BUNDELA ${ }^{1}$, JAYANT KUMAR ${ }^{2}$, ND SONI ${ }^{2}$, RAGHUVEER CHOUDHARY ${ }^{3}$, RAJNEE ${ }^{1}$ \\ ${ }^{1}$ Senior Demonstrator, Department of Physiology, SN Medical College, Jodhpur (Raj), India \\ ${ }^{2}$ Professor, Department of Physiology, SN Medical College, Jodhpur (Raj), India \\ ${ }^{3}$ Associate Professor, Department of Physiology, SN Medical College, Jodhpur (Raj), India
}

\begin{abstract}
It is an established fact that life-style related behavioral factors are mainly responsible for cardiovascular diseases. Doctors are playing very important role in imparting knowledge to the society as to how to stay away from diseases by adopting preventive measures. We studied the prevalence of life-style related risk behavior in medical students and to determine the effect of these factors on blood pressure.

The study was conducted on 249 medical students, from which 182 were boys and 67 were girls of age group 16-29 years. In a random cross-sectional survey of medical students were interviewed for anthropometric measurements, BMI, dietary habits, physical activity and cardiovascular parameters. Cardiovascular risk factors in boys of medical college are more than girls. Out of 182 boys studied 48 [26.37\%] were having their blood pressure values higher than 130/90 $\mathrm{mm} \mathrm{Hg}$. because of their faulty living/eating habits.

Junk food, cola, alcohol and smoking is on rising trend with predominance of physical inactivity and overweight and as a consequence rise in the blood pressure. Dietary and exercise counseling is required for such students.
\end{abstract}

Keywords: Anthropometric indices, BMI, Blood pressure

(Bangladesh J Physiol Pharmacol 2014;30(2):1-8)

\section{INTRODUCTION}

Medical students of today will be the healthcare providers of tomorrow. Their perceptions regarding prevention of diseases will strongly motivate the future clinical practice. It is well known that dietary modification along with control of weight and blood pressure among other factors are important determinants of cardiovascular risk.

Recent data from all over the world indicate that mortality from CVD is increasing and almost doubled in last fifty years. The unfavorable trend is partially attributed to increased prevalence of obesity as indicated by existing literature. These overweight adults have shown much higher blood pressure readings in comparison to their lean and normal weight counterparts.

With growing urbanization, socio-developmental changes have taken place over last $40-50$ years. Dramatic changes in life-style from traditional to modern have lead to physical inactivity due to technological advances. Rising affluence has modified the dietary

Address for correspondence: $\mathrm{Dr}$ Rajnee, Department of Physiology, Dr. S.N. Medical College, Jodhpur, Rajasthan. Email: rajnee_ch@yahoo.co.in pattern. Furthermore, increasing population growth and technological advances have lead to stress, obesity and hypertension in young persons, including students. The various studies estimated a prevalence rate of increase in blood pressure among urban population ranging from $1.24 \%$ in 1949 to $36.4 \%$ in 2003 and rural people from $1.99 \%$ in 1958 to $21.2 \%$ in $1994 .{ }^{1,2}$

This study highlights a need to promote better lifestyle practices in terms of implementation of knowledge to promote health, better dietary practices and improved physical activity in medical students. The attitude and behavior of medical students influences their manner and approach to practice of medicine in the future. Thus it is imperative that medical students should be educated regarding knowledge of risk factors of CVD, to enable them to practice and adopt a healthy lifestyle and hence become prevention-oriented and more productive physicians.

\section{MATERIALS AND METHODS}

To determine the prevalence of cardiovascular risk behavior among medical students, present study was conducted on 249 students of Dr. SN Medical College, Jodhpur, Rajasthan. In a random cross-sectional survey of medical students were interviewed for frequency of 
consumption of vegetables, salad and fruits, fast foods, carbonated soft drinks.

Time in hours spent in physical and sedentary activity was noted. Students with physical activity of less than 30 minutes per day or less for two days or less per week are classified under sedentary or inactive students. Students with 30 minutes activity per day for more than 4 days per week were classified as active students. History regarding consumption of tobacco in any form (gutka, cigarette etc.) and alcohol was also recorded.

\section{MEASUREMENT OF HEIGHT AND WEIGHT}

Height and weight of students were recorded in light clothing without shoes. Height was recorded to the nearest of $0.5 \mathrm{~cm}$ using Stadiometer while the subject barefooted with his head in horizontal plane, and the body weight was recorded to the nearest of $100 \mathrm{gm}$.

The BMI (Body Mass Index) was then calculated as weight in kilograms divided by square of height in meters. Depending upon the BMI values the students of each group were then classified into 4 categories (both boys and girls were grouped separately).

As per recommendation of WHO for Asian population:-
1. Lean or underweight :
$<18.5 \mathrm{~kg} / \mathrm{m} 2$
2. Normal weight:
$18.5-23 \mathrm{~kg} / \mathrm{m} 2$
3. Overweight:
$>23-25 \mathrm{~kg} / \mathrm{m} 2$
4. Obese:
$>25 \mathrm{~kg} / \mathrm{m} 2$

\section{PROCEDURE OF MEASURING BLOOD PRESSURE -}

Blood pressure was measured in the seated position by using mercury sphygmomanometer with the right forearm horizontal on the table. The readings were taken twice and recorded at the interval of 2-3 minutes and the cuff was deflated between the readings. The mean of two readings were calculated and considered for final analysis.

All these data were analyzed statistically to determine as to what extent these unhealthy behavioral practices/cardiovascular risk behaviors are prevalent in medical students.

\section{RESULT}

TABLE I

Factors affecting cardiovascular system

\begin{tabular}{|l|c|c|}
\hline Parameters & Boys & Girls \\
\hline Obesity Status [BMI > 23] & $37.35 \%$ & $19.39 \%$ \\
\hline Fruits/Veg. serving/day & $21.43 \%$ & $32.84 \%$ \\
\hline Carbonated Drinks consumers & $61.00 \%$ & $41.80 \%$ \\
\hline Alcohol consumers & $22.00 \%$ & $04.48 \%$ \\
\hline Smokers & $07.15 \%$ & $\mathrm{Nil}$ \\
\hline No Exercise & $24.47 \%$ & $46.26 \%$ \\
\hline Light to Moderate Exercise & $69.22 \%$ & $52.23 \%$ \\
\hline Higher Blood Pressure Values $[>130 / 90]$ & $26.37 \%$ & $4.47 \%$ \\
\hline
\end{tabular}

Table I shows that prevalence of above mentioned cardiovascular risk factors in boys of this medical college is more than girls. High prevalence of cardiovascular risk factors results into increase in blood pressure. Out of 182 boys studied 48 [26.37\%] were having their blood pressure values higher than 130/90 mm Hg, because of their faulty living/eating habits. 
Assessment of Cardiovascular Behavioural Risk Factors in Medical Student

TABLE II

Mean SBP \& DBP observed in boys and girls

\begin{tabular}{|c|c|c|c|c|c|c|}
\hline \multirow{2}{*}{} & \multicolumn{2}{|c|}{ Males } & \multicolumn{2}{c|}{ Females } & \multicolumn{2}{c|}{ All Students } \\
\cline { 2 - 7 } & SBP & DBP & SBP & DBP & SBP & DBP \\
\hline Mean & 128.09 & 84.8 & 118.25 & 80.13 & 125.45 & 83.55 \\
\hline SD & 10.5 & 9.36 & 10.97 & 9.39 & 11.47 & 9.58 \\
\hline
\end{tabular}

Table II Mean Blood pressure reference values in boys were $128.09 \pm 10.05 / 84.8 \pm 9.36 \mathrm{~mm} \mathrm{Hg}$, in girl's $118.25 \pm 10.97 / 80.13 \pm 9.39 \mathrm{~mm} \mathrm{Hg}$. and in all students irrespective of gender were $125.45 \pm 11.47 / 83.55 \pm 9.58 \mathrm{~mm}$ $\mathrm{Hg}$.

Table III

Effect of Obesity on Blood Pressure in Boys \& Girls

\begin{tabular}{|c|c|c|c|c|c|c|}
\hline \multirow{3}{*}{ BMI } & \multicolumn{6}{|c|}{ Boys } \\
\hline & \multicolumn{3}{|c|}{ SBP } & \multicolumn{3}{|c|}{ DBP } \\
\hline & Mean & SD \pm & $P$ value & Mean & SD士 & P value \\
\hline$<18.5[n=29]$ & 124.34 & 11.99 & $p=0.33$ & 82.56 & 8.86 & $\mathrm{P}=0.19$ \\
\hline $18.5-23[n=85]$ & 126.45 & 9.49 & $\begin{array}{l}\text { Treated as } \\
\text { Control }\end{array}$ & 84.68 & 7.63 & $\begin{array}{l}\text { Treated as } \\
\text { Control }\end{array}$ \\
\hline $23-25[n=44]$ & 130.36 & 11.21 & $P=0.04$ & 87.79 & 10.79 & $p=0.05$ \\
\hline$>25[n=24]$ & 133.92 & 7.04 & $p=0.0005$ & 93.33 & 7.9 & $p=0.000009$ \\
\hline \multirow{3}{*}{ BMI } & \multicolumn{6}{|c|}{ Girls } \\
\hline & \multicolumn{3}{|c|}{ SBP } & \multicolumn{3}{|c|}{ DBP } \\
\hline & Mean & SD \pm & P value & Mean & SD \pm & P value \\
\hline$<18.5[n=14]$ & 116.28 & 11.99 & $P=0.63$ & 79.57 & 10.79 & $P=0.9$ \\
\hline $18.5-23[n=40]$ & 117.75 & 9.06 & $\begin{array}{l}\text { Treated as } \\
\text { Control }\end{array}$ & 80 & 9.37 & $\begin{array}{l}\text { Treated as } \\
\text { Control }\end{array}$ \\
\hline $23-25[n=1]$ & 119.55 & 14.91 & $\mathrm{P}=0.84$ & 78.64 & 6.36 & $P=0.9$ \\
\hline$>25[n=2]$ & 135 & 1.41 & $P=0.01$ & 95 & 1.41 & $P=0.03$ \\
\hline
\end{tabular}

Table III shows that with the rise in BMI [> 25] there is significant increase in SBP [133.92 \pm 7.04$]$ and DBP [93.33 \pm 7.9 ] in boys [with $P$ value $<0.0005$ and $<0.00009$ respectively]. In girls [with BMI $>25$ ] also, there is significant rise in SBP [135 \pm 1.41$]$ and DBP [95 \pm 1.41$]$ with $P$ value $<0.01$ and $<0.03$ respectively. (Chart $1 \& 2$ ) 


\section{Table IV}

Effect of Exercise on SBP \& DBP in Boys \& Girls

\begin{tabular}{|c|c|c|c|c|c|c|}
\hline \multirow{3}{*}{ Exercise } & \multicolumn{6}{|c|}{ Boys } \\
\hline & \multicolumn{3}{|c|}{ SBP } & \multicolumn{3}{|c|}{ DBP } \\
\hline & Mean & SD \pm & P value & Mean & SD \pm & $P$ value \\
\hline Nil $[n=50]$ & 128.72 & 11.96 & $\begin{array}{l}\text { Treated as } \\
\text { Control }\end{array}$ & 85.92 & 10.05 & $\begin{array}{l}\text { Treated as } \\
\text { Control }\end{array}$ \\
\hline Light $[\mathrm{n}=77]$ & 128.02 & 10.72 & $P=0.73$ & 84.46 & 8.95 & $P=0.39$ \\
\hline Moderate $[n=49]$ & 128.24 & 7.44 & $P=0.81$ & 85.38 & 9.18 & $P=0.78$ \\
\hline Severe $[n=6]$ & 117 & 2.09 & $P=0.01$ & 75 & 2.75 & $P=0.01$ \\
\hline \multirow{3}{*}{ Exercise } & \multicolumn{6}{|c|}{ Girls } \\
\hline & \multicolumn{3}{|c|}{ SBP } & \multicolumn{3}{|c|}{ DBP } \\
\hline & Mean & SD \pm & P value & Mean & SD \pm & P value \\
\hline $\operatorname{Nil}[n=31]$ & 115.96 & 11.62 & $\begin{array}{l}\text { Treated as } \\
\text { Control }\end{array}$ & 78.74 & 10.09 & $\begin{array}{l}\text { Treated as } \\
\text { Control }\end{array}$ \\
\hline Light $[n=25]$ & 119.20 & 10.77 & $P=0.28$ & 80.00 & 7.64 & $P=0.60$ \\
\hline Moderate $[n=11]$ & 122.54 & 08.49 & $P=0.09$ & 84.36 & 10.50 & $P=0.12$ \\
\hline Severe $[n=0]$ & - & - & - & - & - & - \\
\hline
\end{tabular}

As shown in Table IV, Exercise [brisk] significantly and favorably affects i.e. reduces SBP [117 \pm 2.09 ] and DBP $[75 \pm 2.75]$ with $\mathrm{P}$ value $<0.01$ in boys. No data No data available in girls as they don't perform brisk exercise. (Chart 3\&4)

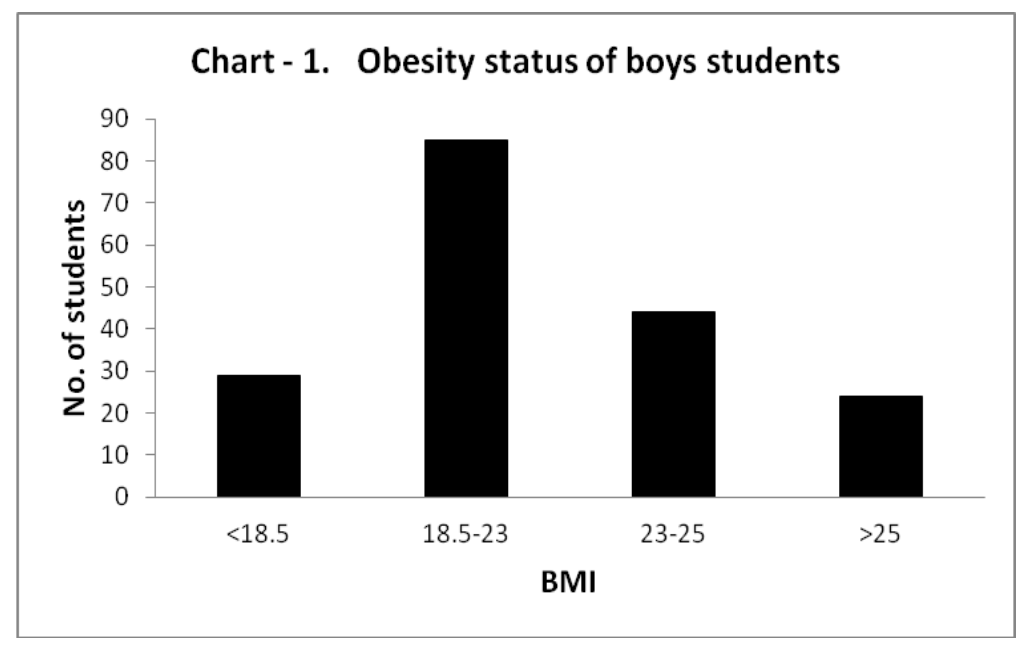



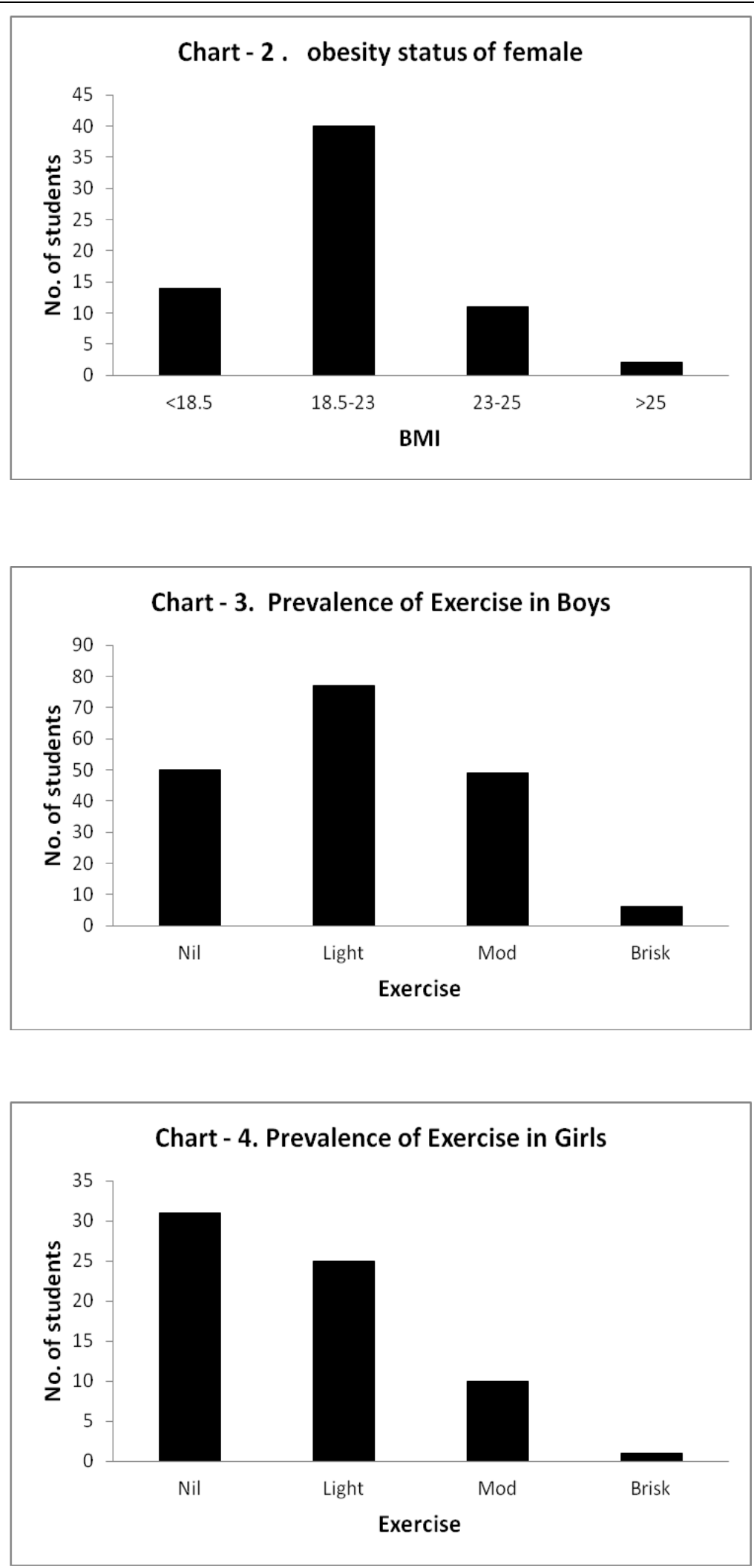


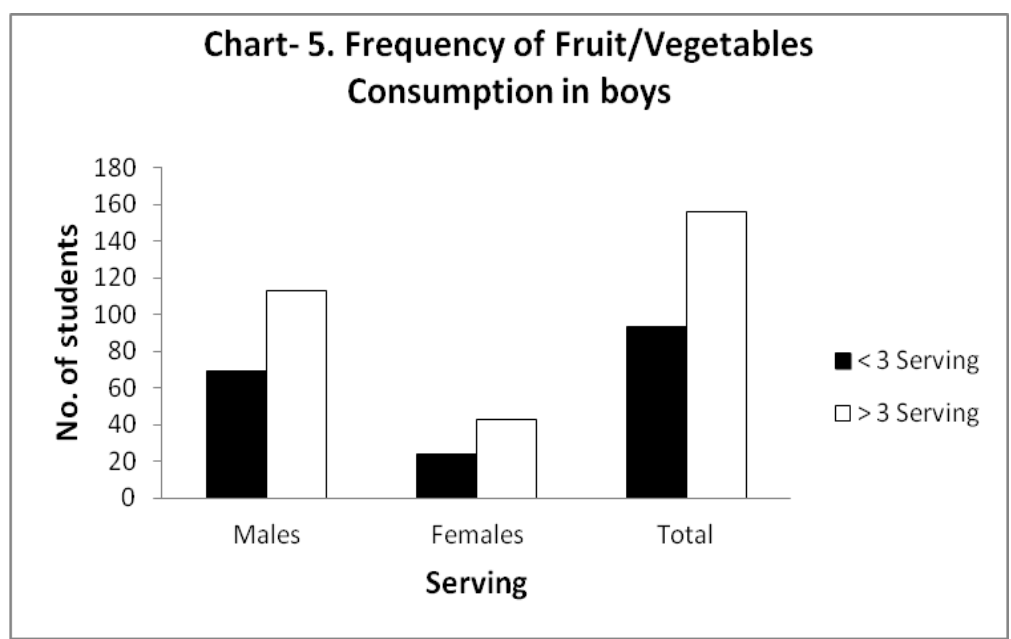

\section{DISCUSSION}

Through this study we tried to assess the cardiovascular predisposing factors, health dietary behavior and perceptions of the medical students in our college. We found a slightly high prevalence of physical inactivity, smoking, alcoholism, carbonated drinks consumption and inappropriate fruit and vegetable consumption in medical students especially boys. All these factors are established causative reasons in raising BMI and Blood Pressure values.

Fruits and vegetables play vital role in improving general health. Fruits/vegetable consumption is inversely related to total cholesterol and low density lipoprotein cholesterol and with risk of cardiovascular diseases. $^{3}$

In our study, [Table I, Chart - 5] we found that only $21.43 \%$ of boys and $32.84 \%$ of girls were consuming 5 or more servings of fruits and vegetables per day. This was much lower than the findings in Pakistan and Greece respectively. ${ }^{4,5}$ These findings reflect poor dietary awareness among our medical students in comparison to other countries. Fruit and vegetables consumption is gradually replaced with fast foods or ready to eat foods as student progress through the medical college. Poor food habits and excess salt intake was also reported by. ${ }^{6}$ This is a matter of concern as stay in medical college and study of community medicine did not promote healthy behavior among students. Awareness about positive effects of fruits and vegetables over health is well known to medical students but little effort is taken by them to modify their lifestyle.

Smoking is one of the most important risk factors for developing cardiovascular disease. In present study [Table I] prevalence of cigarette smoking was $7.15 \%$ in boys [cf. nil in case of girls] which was lower than that found in previous studies. ${ }^{7-9}$ Raza et al $2010^{10}$ found smoking prevalence in $9.4 \%$ students. The incidence is much higher in western countries where students are regular smokers. ${ }^{11,12}$

The prevalence of Alcohol Drinking was found [Table I] to be $22 \%$ in boys and only $4.48 \%$ in girls. Use of tobacco and alcohol significantly increases with increase in semester of students and more and more number of boys consume these in comparison to girls. Rustogi et al $(2012)^{13}$ in their study in medical college at Delhi, reported alcohol consumption by boys and girls as $33.5 \%$ \& $22.2 \%$ respectively and smoking $9.1 \%$ \& 3.7\% in boys $\&$ girls respectively. Tobacco smoking and alcohol consumption reportedly increased among medical students between the year of entry and final year. ${ }^{14,15}$

Physical activity is the major determinant of health. Physical activity exceeding the minimum recommended amount helps improve physical fitness, reduces the risk of chronic diseases and disability and help prevent unhealthy weight gain. ${ }^{16}$ The level of physical activity among the medical students was not satisfactory. $24.47 \%$ boys \& $46.26 \%$ girls [Table I] were not doing any kind of physical activity at all. $69.22 \%$ boys \& $52.23 \%$ girls were doing light to moderate exercise. Only $3.29 \%$ boys \& $1.49 \%$ girls were doing recommended ${ }^{17,12}$ amount of physical activity. Our findings are much lower than the earlier findings. ${ }^{8,18}$ Another study found $37.9 \%$ students having low physical activity in their study. ${ }^{10}$

Physical activity of doctors and medical students is not only important from a personal point of view but it also affects their counseling of patients. It has been shown that doctors who act on the advice they give themselves, provide better counseling and motivation of their patients to adopt such health advice. ${ }^{19}$ It is therefore imperative that medical schools/colleges 
increase the proportion of students adopting and maintaining regular physical activity habits in order to increase the rates and quality of future physical activity counseling delivered by doctors.

Obesity - As per WHO recommendations, we labeled subjects having BMI values of 18.5 to 23 as normal weight and statistically compared the blood pressure measurements of this group with the other BMI groups [underweight or lean (BMI < 18.5), overweight (BMI > 23-25) and obese (BMI > 25)] and found that fall in blood pressure readings in underweight subjects were not significant but increase in blood pressure in overweight and obese subjects of both sexes was found to be highly significant.

In our study [Table I] , we found that $46.7 \%$ boys were in the normal BMI range as against $59.7 \%$ girls. On the other hand $37.35 \%$ boys were found overweight/obese in contrast to $19.39 \%$ girls only. There was not much difference in the lean population of boys [15.93\%] and girls [20.89\%].

Our observations suggests that females were more conscious of their diet [consuming more fruits/vegetables, less junk food, less cola, less smoking alcohol] as compared to boys. Boys are getting more energy from junk food, cola, alcohol, less physical activity and therefore getting obese.

Increased BMI was found to be associated with increased blood pressure.20 Sedentary life-style and fast-food consumption were important factors for blood pressure rise in both males and females. ${ }^{20}$

Blood Pressure - Normal reference blood pressure values in our study was found to be $128.09 \pm 10.05 / 84.8 \pm 9.36 \mathrm{~mm} \mathrm{Hg}$. in boys, $118.25 \pm 10.97 / 80.13 \pm 9.39 \mathrm{~mm} \mathrm{Hg}$. in girls and $125.45 \pm 11.47 / 83.55 \pm 9.58 \mathrm{~mm} \mathrm{Hg}$ in all students irrespective of gender [Table II].

Our study [Table II and III] shows that with the rise in BMI [ $>$ 25], there is significant increase in SBP [133.92 $\pm 7.04 \mathrm{~mm}$. Hg.] and DBP [93.33 $\pm 7.9 \mathrm{~mm}$. Hg.] in boys with $\mathrm{P}$ value $<0.0005$ and $<0.00009$ respectively. In girls having $\mathrm{BMI}>25$, there is also significant rise in SBP [135 $\pm 1.41 \mathrm{~mm}$. $\mathrm{Hg}$.] and DBP $[95 \pm 1.41 \mathrm{~mm}$. Hg.] with $\mathrm{P}$ value $<0.01$ and $<0.03$ respectively.

Further our study [Table IV] also shows that students doing recommended amount of exercise [brisk exercise for 30 minutes for at least 5 days per week] are having significantly less blood pressure values $[117 \pm 2.09 / 75.8 \pm 2.75 \mathrm{~mm} \mathrm{Hg}$ with a $\mathrm{P}$ value $<0.01]$. No data available in girls as they are not doing brisk exercise.
In our study $26.37 \%$ boys were having blood pressure values more than $130 / 90 \mathrm{~mm} . \mathrm{Hg}$. in contrast to only $4.47 \%$ girls having higher values as is evident by following table -

$\begin{array}{lllll}\text { Parameters } & \text { Boys } & \text { \% } & \text { Girls } & \text { \% } \\ \begin{array}{l}\text { Blood Pressure } \\ <130 / 90 \mathrm{~mm}\end{array} & 134 & 73.63 & 64 & 95.53 \\ \mathrm{Hg} & & & & \\ \begin{array}{l}\text { Blood Pressure } \\ >130 / 90 \mathrm{~mm} \\ \mathrm{Hg}\end{array} & 48 & 26.37 & 3 & 4.47 \\ \begin{array}{l}\text { Total Students } \\ \text { Tg }\end{array} & 182 & 100 & 67 & 100\end{array}$

These high blood pressure values in boys might be due to faulty eating/living habits, lack of recommended amount of exercise and obesity. Similar results were presented in a study conducted earlier. ${ }^{10}$ They recorded elevated blood pressure in $27.3 \%$ students. [11.4\% students had blood pressure in the range of $120-$ $139 / 80-89 \mathrm{~mm} \mathrm{Hg}$ and $15.9 \%$ had blood pressure > $140 / 90 \mathrm{~mm} \mathrm{Hg}$.

\section{CONCLUSION}

We have tried to assess the dietary and life style of medical students, who represent the community of future health practitioners. Improvement in lifestyle if made early years and during medical schooling would produce physicians practicing and promoting healthy diet and active life style.

\section{ACKNOWLEDGEMENT}

\section{REFERENCES}

1. Nissien A, Bothig $S$, Grenroth $H$, Lopez AD. Hypertension in developing countries. World Health State Q 1988; 41: 141-154.

2. Reddy KS. Hypertension control in developing countries generic issues. J Hum Hypertension 1996; 10: 533-538.

3. Mirmiran $\mathrm{P}$, Noori $\mathrm{N}$, Zavareh $\mathrm{MB}$, Azizi F. Fruit and vegetable consumption and risk factors for cardiovascular disease. Metabolism 2009; 58: 460-468.

4. Nisar $\mathrm{N}$, Qadri MH, Fatima K, Perveen S. Dietary habits and life style among the students of a private medical university Karachi. ] Pak Med Assoc 2008; 58: 687-690.

5. Bertsias G, Mammas I, Linardakis M, Kafatos A. Overweight and obesity in relation to cardiovascular disease risk factors among medical students in Crete, Greece. BMC Public Health 2003; 3: 3.

6. Skemiene L, Ustinaviciene $\mathrm{FL}$, Piesine $\mathrm{L}$, Radisauskas $\mathrm{R}$. Pecularities of medical students' nutrition. Medicina [Kaunas] 2007; 43: 145-152.

7. Binu VS, Subba SH, Menezes RG, Kumar G, Ninan J, Rana MS, Chhetri SK, Sabu KM, Nagraj K. Smoking among Nepali youth-prevalence and predictors. Asian Pac J Cancer Prev 2010; 11: 221226.

8. Giri S, Sharma SR, Timalsina S, Yadav V, Koirala S, Kumar A, Neupane S, Neupane M. Cardiovascular Health Risk Behavior 
among Medical Students in a Teaching Hospital. J Nepal Health Res Counc 2012; 10: 187-191.

9. Sreeramareddy $C T$, Suri $S$, Menezes RG, Kumar $H H$, Rahman $M$, Islam MR, Pereira XV, Shah M, Sathian B, Shetty U, Vaswani VR. Self-reported tobacco smoking practices among medical students and their perceptions towards training about tobacco smoking in medical curricula: A cross-sectional, questionnaire survey in Malaysia, India, Pakistan, Nepal, and Bangladesh. Subst Abuse Treat Prev Policy 2010; 16: 29.

10. Raza S, Sheikh MA, Hussain MFA, Siddiqui SE, Muhammad R, Qamar S, Saleem MA, Waki N, Faruqi H, Zia A. Dietary modification, Body Mass Index (BMI), Blood Pressure (BP) and cardiovascular risk in medical students of a government medical college of Karachi. JPMA 2010; 60: 970-974.

11. Poreba R, Gac P, Zawadzki M, Poreba M, Derkacz A, Pawlas K, et al. Life style and cardiovascular risk factors among students of Wroclaw postgraduate schools. Pol Arch Med Wewn 2008; 118: 102-110.

12. Najem GR, Passannante MR, Foster JD. Health risk factors and health promoting behavior of medical, dental and nursing students. J Clin Epidemiol 1995; 48: 841-849.

13. Rustagi N, Taneja DK, Mishra P, Ingle GK. Cardiovascular Risk Behavior among Students of a Medical College in Delhi. Indian J Community Med 2011; 36: 51-53.

14. Ramakrishna GS, Sankara Sarma P, Thankappan KR. Tobacco use among medical students in Orissa. Natl Med J India 2005; 18: 285-289.

15. Singh SK, Narang RK, Chandra S, Chaturvedi PK, Dubey Al. Smoking habits of the medical students. Indian J Chest Dis Allied Sci 1989; 31: 99-103.

16. Haskell WL, Lee IM, Pate RR, Powell KE, Blair SN, Franklin BA. Physical activity and public health: updated recommendation for adults from the American College of Sports Medicine and the American Heart Association. Circulation 2007; 116: 1081-1093.

17. Delnevo CD, Abatemarco DJ, Gotsch AR. Health behaviors and health promotion/disease prevention perceptions of medical students. Am J Prev Med 1996; 12: 38-43.

18. Aslam F, Mahmud $H$, Waheed A. Cardiovascular health behavior of medical students in Karachi. J Pak Med Assoc 2004; 54: 492-495.

19. Lobelo F, Duperly J, Frank E. Physical activity habits of doctors and medical students influence their counselling practices. $\mathrm{Br}]$ Sports Med 2009; 43: 89-92.

20. Malhotra P, Kumari S, Kumar R, Sharma BK. Prevalence and determinants of hypertension in un-industrialized rural population of North India. J Hum Hypertension 1999; 13: 467-472. 